\title{
IGiS FOR MANAGING CITIES SMARTLY - URBAN GEOINFORMATICS
}

\author{
Pushpalata Shah
}

Scanpoint Geomatics Limited, Ahmedabad, Gujarat, India

\begin{abstract}
KEY WORDS: IGiS, Spatial Database, Standardisation, HRSI, IoT, Sensors, APIs, ICCC
\end{abstract}
\section{ABSTRACT:}

A city is a geographic entity and should be efficiently analysed and optimised through the use of geo-spatial technology. The certification for a city to be 'Smart' is measured on the basis of the liveable index, adequacy of water supply, assured supply of electricity, proper sanitation and solid waste management, efficient urban mobility, public transport, affordable housing, robust information technology connectivity, transparent and good governance, safety and security of citizens, modernised health and education infrastructure and citizen participation which will lead to sustainable development. Smart Cities require a perfect balancing of modernisation of city infrastructure and leveraging technology. Smart cities require Geo-smart mapping and visualization capabilities with applications for protecting groundwater resources, locating schools and health centres, locating garbage dumps and toilets, designing bus routes. The indigenously developed integrated platform of GIS, Image Processing, Photogrammetry and CAD, called IGiS has been leveraged by Scanpoint Geomatics Limited, Ahmedabad (SGL), India for implementing the Enterprise GIS for 7 smart cities in India. A centralised geo spatial database with a standard data model compliant set of maps/layers has been created for each city. The spatial layers are derived from $30 \mathrm{~cm}$ resolution satellite data. Point data (locational information) is generated using DGPS surveys. The city assets are geographically mapped at a scale of 1:2000 and organised in a spatial database. Inputs required for operations and maintenance of every utility/facility are geo tagged and stored in the database. Web \& Mobile GIS applications \& Citizen portal are developed using the indigenous platform. Integration with other e-governance applications and spatial layer requirements of the Integrated Command and Control Centre are supported through RestAPI \& OGC compliant web services. SGL's Mobile GIS framework named Qpad comes handy for spatial data verification. IoT devices are used to gain insights for real-time handling of critical situations or emergencies. Having laid the foundation for driving smart cities in terms of the spatial database at a scale of 1:2000, the stage is set to look forward to the results. Plugging revenue leakages, better traffic management, information at a click during peak of the Corona pandemic, effective usage of open spaces and barren areas, planning the utility requirements by the corporation to accommodate for the urban explosion is the kind of harvest that is anticipated with abated breath. This paper demonstrates the suitability and capability of the indigenously developed common platform for image processing and GIS (IGiS Enterprise Suite) in building Smart City Applications and quantifying the results.

\section{INTRODUCTION}

\subsection{Background}

Government of India's Smart City Mission focuses on redefining urban development initiatives that make cities more liveable, inclusive and centres of economic growth. A 'smart city' should include adequate water supply; assured electricity; sanitation, including solid waste management; efficient urban mobility and public transport; affordable housing, especially for the poor; robust Information Technology connectivity and digitalization; good governance, especially citizen participation; sustainable environment; safety and security of citizens; and, health and education. This needs a balanced focus in terms of modernising city infrastructure and leveraging technology.

A city being a geographic entity can be efficiently analysed and optimised through the use of geo-spatial technology. John Whitehead, Director, Asia Pacific- Geospatial of Trimble said that smart cities start with smart projects as they are the precursor to spatially intelligent cities. The past, the present and the future of the city infrastructure and utilities have to be diligently mapped and organised in a Geographical Information System (GIS) for achieving a sustainable habitat. GIS can efficiently model the 'real world' of the city in totality. The journey of developing a smart city is eased by usage of emerging tools like GIS, which drive the smart cities to move ahead. Smart cities require Geo-smart mapping and visualization capabilities with applications for protecting groundwater resources, locating schools and health centres, locating garbage dumps and toilets, designing bus routes.

\subsection{The IGiS Product}

Scanpoint Geomatics Limited, Ahmedabad (SGL), India has been involved in the implementation of Enterprise GIS for 7 smart cities, which leverages its own indigenously developed integrated platform of GIS, Image Processing, Photogrammetry and $\mathrm{CAD}$, called IGiS for creating spatial data infrastructure (Figure_1). Enterprise GIS implemented on IGiS platform acts as single source of truth for city administration by way of end-toend data management and analysis of spatial \& non spatial data. In all the cities centralised GIS data base is created as per standardised data model. The spatial layers are derived from $30 \mathrm{~cm}$ resolution satellite data. Point data (locational information) is generated using DGPS surveys. The city assets are geographically mapped at a scale of 1:2000 and organised in a spatial database. Inputs required for operations and maintenance of every utility/facility are geo tagged and stored in the database. To effectively utilise the data for planning, operation and information dissemination, Web \& Mobile GIS applications \& Citizen portal are developed on IGiS. RestAPI \& OGC compliant web services are provided from the indigenous IGiS platform for the purpose of integration with other e-governance applications. 


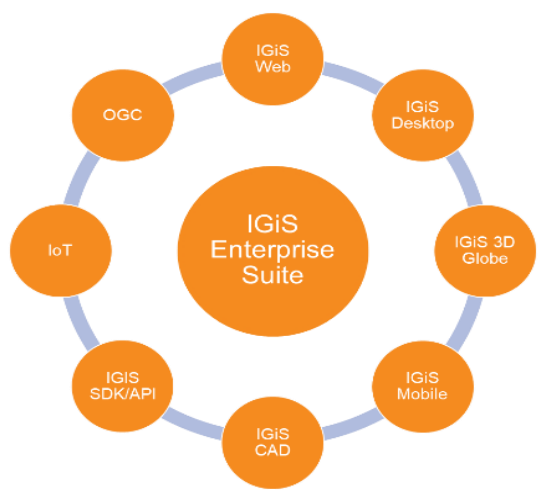

Figure_1: IGiS Enterprise Suite

Smartness in operations and management of utility related infrastructure is achieved through use of IoT devices/sensors. Most of the smart city projects have installed environmental sensors, variable message sign boards, cameras for surveillance, solid waste management system, smart electricity meters, smart parking systems, GPS enabled city buses and intelligent traffic systems. Monitoring and maintenance of every subsystem is synergised at the Integrated Command \& Control Centre.

\subsection{INFRASTRUCTURE SETUP:}

\subsection{Assisting Technologies}

Management of smart cities requires a mashup of technologies like smart sensors, internet, network enabled devices, satellite data, and geoinformatics. The smart city projects referred to in this paper are founded on the geomatics capabilities of the IGiS project in conjunction with the Internet. The IGiS Enterprise Suite provides the spatial data linking while connecting the signals from the IoT devices and smart sensors to the ICCC as depicted in Figure_2. The maps or required layers are served to the ICCC using the REST APIs of IGiS.

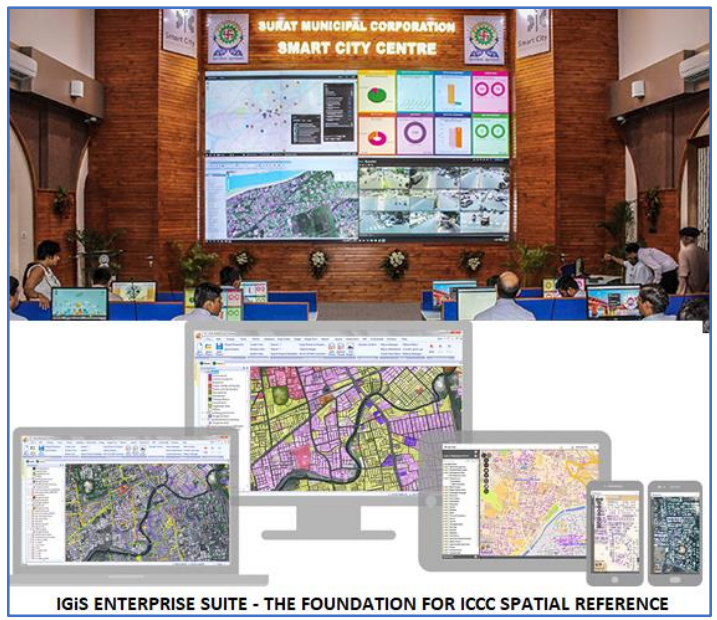

Figure_2: IGiS Enterprise Suite for Spatial Linking

Technology performs the pivotal role which analyses, automate and integrate the various aspects for sustainable city development. Network of sensors, cameras, wireless devices, and data centres form the key infrastructure, which allows civic authorities to provide essential services in a faster and more efficient manner. A smart city provides effective integration of physical, digital and human systems to deliver a sustainable, prosperous and inclusive future for its citizens. GIS technology bridges the gap between different sectors and acts as an integrated cross sectoral platform to collect, manage, compile, analyse and visualize geospatial, temporal information for sustainable urban planning, development and management.

Figure_3 depicts graphically the architecture for the integrated infrastructure that is deployed in the Smart City projects executed by SGL

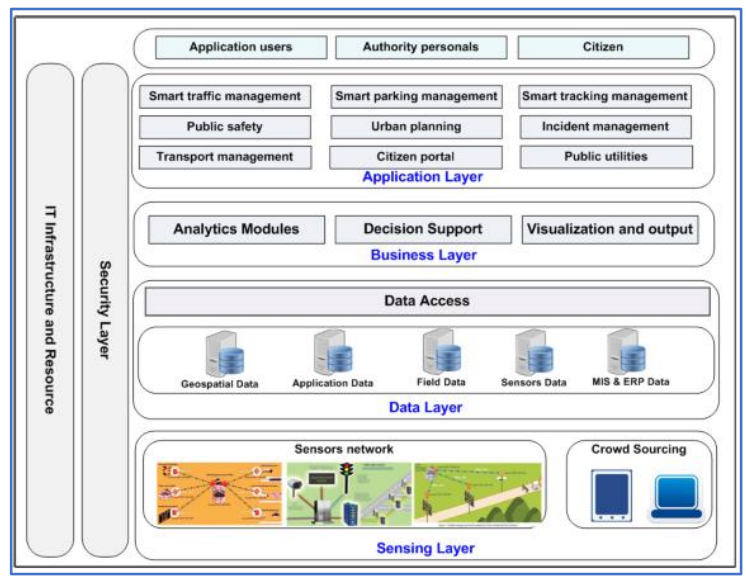

Figure_3: Architecture for the Infrastructure

\subsection{System Solution Architecture:}

Figure_4 displays the smart city solution architecture. It includes the various components that need to function in an integrated manner to operationalise the smart city solution. Data from multiple sources like satellites, flat files, excel sheets, ODBS data and other GIS products can be easily integrated into the IGiS. The requirement of providing OGC compliant web services is fulfilled through the IGiS Publisher. The web services can be accessed from all internet enabled devices with a browser, the requirement of linking of pre-existing information systems with the spatial layers is satisfied through the use of IGiS APIs in the Smart web applications.

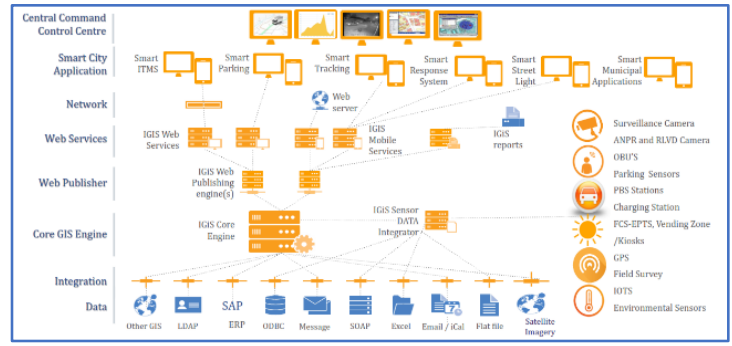

Figure_4: System Solution Architecture

\subsection{SPATIAL DATABASE CREATION:}

\subsection{Spatial Database}

A Smart city is a knowledge-based city functioning on latest and updated information on automated decision-making and rapid action for individuals. GIS technology is used to capture, store and manipulate, analyze and visualize spatially referenced data. It is used for spatial analysis and modeling. A centralized information system based on GIS provides an IT framework for 
maintaining and deploying data and applications throughout every aspect of the city development life cycle.

For Smart Cities, urban databases are created at a scale of 1:2000 as per design and standards defined under AMRUT. The base maps are created using $0.3 \mathrm{~m}$ High resolution Satellite Imagery (HRSI) of the latest date available. The photogrammetric requirements of orthorectification and generating DEMs are met by the Photogrammetry Module. Layers derived from satellite imagery are Building Footprints, Vacant Plots, Road Centerline, Road Polygon, Road Divider, Traffic Island, Footpath, Bridges / flyovers /culverts, Railway Station, Railway Line, Railway Properties, Parks, Gardens, Stadiums, Playgrounds, Green Areas, Open Areas, Streams, Drainage, Rivers, Canal, Ponds, Swimming Pools, and Overhead Tanks. Other locational information is gathered using the Mobile App of QPad.

Maps for utilities like electricity network, water supply, sanitation facilities, storm drainage and solid waste management are prepared from CAD drawings or photographs available with the corporation. Sample maps are given in Figure_5, Figure_6 and Figure_7. Network models are used to monitor and analyze distribution systems of these utilities.

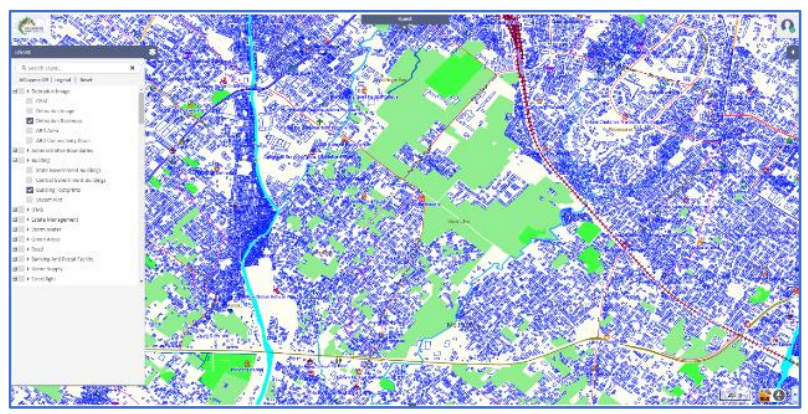

Figure_5: Building Footprints from Satellite Data

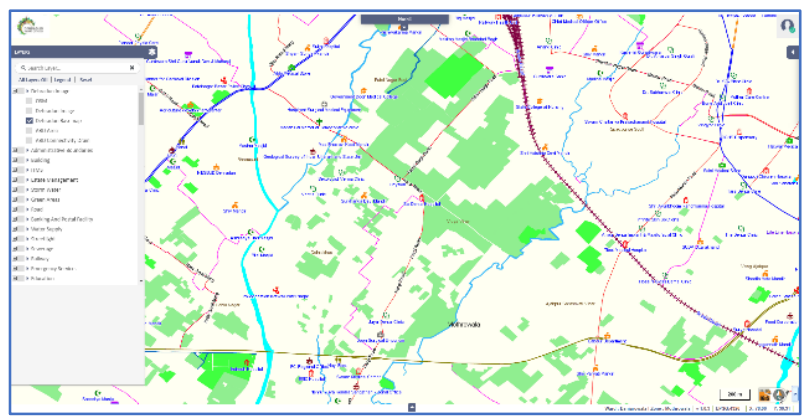

Figure_6: Surveyed Point Data and Road Network from Satellite Data

N.B. All maps displayed here are Courtesy: Dehradun Smart City Limited

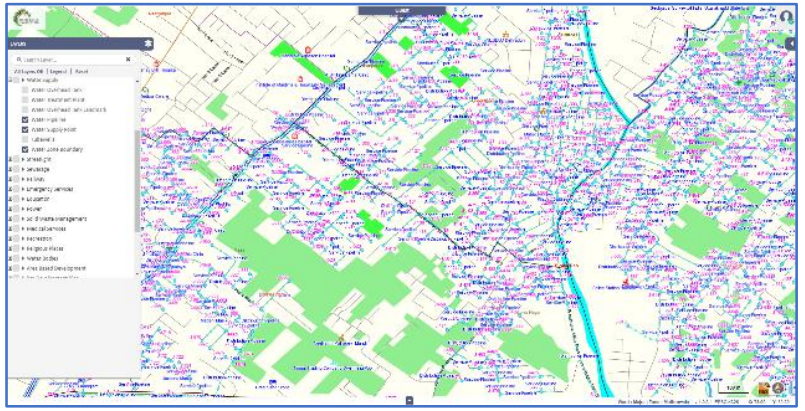

Figure_7: Water Supply Infrastructure Network layer prepared from CAD Drawings

Geo information throughout the lifecycle of a city starts with existing and planned projects, critical infrastructure first, followed by other public assets. Also, updating the geoinformation is a continuous activity.

\subsection{Spatial Data Verification}

SGL's Mobile GIS framework named Qpad has been used extensively for

1. Online field data collection and inspection

2. Geo tagging of Property and attaching geo-tagged images

3. Geo-fencing - people leaving or entering a banned area (quarantined zones)

\subsection{Spatial Data Model:}

The data model defines various categories of spatial layers along with the attributes and the codes to be attached with the attribute for each layer/theme. This brings about a uniformity and consistency in the data structures of all layers across all smart city and urban local body applications.

The data model in a geographic information system (GIS) is a mathematical construct for representing geographic objects or surfaces as data. Various GIS themes (maps/layers) are categorized into classes and sub-classes. The non-spatial attribute information stored in the tables is linked with the spatial / graphical objects through unique keys and codes. The standards laid down in AMRUT guidelines form the baseline for the data model. All additional information especially, data which is dynamic and specific to individual cities is stored in associated tables. The linking of the tables with the spatial layer is done onthe-fly. These tables mostly contain operational attributes of maintenance and repairs.

\subsection{IOT DEVICES AND SENSORS:}

\subsection{Detecting disruptions in services}

The growing penetration of IoT devices and the resultant data provides ample opportunities to gain critical insights for real-time handling of critical situations or emergencies". The sensors currently in use are for automatic number plate recognition and red light violation detection system as part of intelligent traffic management system; Environment sensors, city surveillance cameras, variable message system, public announcement systems, and emergency call boxes are in place for betterment of citizen security, timely information and emergency response. 
Supervisory control and data acquisition (SCADA) systems are also deployed in electric utilities, operations and management of water, wastewater and sewage and so on. Equipment can be monitored in real time, thereby enabling proactive maintenance and decreasing downtime. The location of the IoT devices are stored as maps for smooth and quick spatial referencing of the IoT data.

\subsection{APIs for Information Integration}

The convergence of GIS and IoT technology results in the smart solution for the city through customised applications for smart street lighting, smart parking, smart education, smart poles, smart electrical and water metering, intelligent building management, intelligent traffic management, smart management of water and sewerage services including leak detection, septage management and so on. The ICCC application has a built-in map control which consumes the OGC services from the centralised geo-spatial server. Additionally, callable REST APIs provide incident based spatial data linking for decision making (Figure_8).

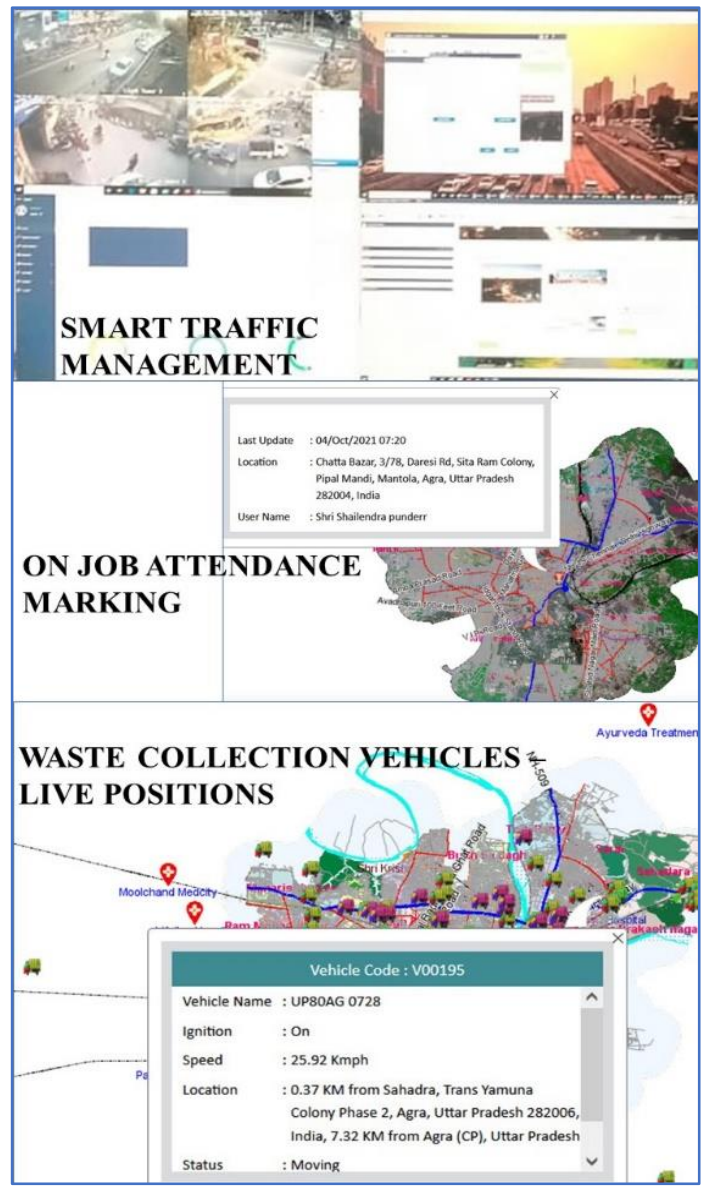

Figure_8: API based applications

The citizen participation is enabled through a citizen portal with overall city details and a handle for logging grievances and redirecting the same to concerned departments of the corporation for necessary action.

Additionally, existing e-governance solutions available with the corporation are smoothly integrated with the geo-spatial data for utility billing management, property tax, advertising and hoarding management, building permissions, mobile towers regulation system, and registration and licensing.

\subsection{GIS BASED ANALYSIS:}

\subsection{Analysis through Spatial Queries}

A city is discovered by locals and outsiders through queries like 'What lies around me?' and 'Shortest path to reach a destination'. Such features have been established using the Buffer and Road Network analysis in the Citizen Portal.

IoT based ANPR (automated Number Plate Monitoring) sensors, live video monitoring of Traffic junctions and integrating ITMS related layers through REST APIs, have been implemented for automated speed ticketing. This has resulted in better traffic sense among citizens and additional revenue through fines, for the corporation.

The implementation of IoT based sensors for providing online information about available parking spaces is under progress.

Similarly, SCADA based systems are being used for Intelligent Management of Street Lights, Maintenance and Repairs of underground utility networks and Power Supply departments.

Data from Environmental Sensors is shared in a consumable format with citizens. The database is maintained for studying pollution and temperature patterns and planning damage control measures.

The platform established for the Smart City portals has been used in the current pandemic for sharing information related to Corona care. This includes monitoring the movement of infected persons using the GPS of the patient's mobile phone and setting up alarms. Providing online information related to availability of beds and ICUs at city level and location based information related to location of testing facilities during the peak of the pandemic and highlighting locations of availability of essentials. Citizens were informed about areas to be avoided through live and dynamic Heat maps indicating concentration areas of infected persons.

\subsection{Advantages}

Space technology has been used for extracting exact building foot prints from satellite data. The footprints are geo-tagged, and the spatial layer is linked with property tax data of the Municipal Corporation. This has brought out all the unregistered properties which are taken up by the Corporation for further action. Often it is observed that revenue leakage happens by the way of nonpayment of any of the taxes like water tax, electricity tax or property tax. Integration of spatial data with the information system of individual departments brings out these anomalies and enables plugging in the revenue leakage.

The building foot prints in conjunction with land use provide availability of open spaces and land which can be judiciously planned for optimal utilisation and enhancing infrastructure in the city (augmenting community services).

Citizen participation is extended through online citizen grievance cell for the facilities provided by the city corporation through a mapping interface. Geo-spatial analytics of grievance management provides insight into the proactive steps required to improve citizen service. 
In the event of any disaster or emergency, GIS capability helps in quickly identifying the impact area, impacted population, vulnerable entities (like schools, religious places, roads, bridges, buildings, hutments, poultry and domesticated animals, etc.) along with available resources to respond helps in swift and efficient disaster management. Availability of DEM (Digital Elevation Model) \& contour data for city geography can effectively be utilised to predict and manage the water logging situation often created in city monsoon due to heavy rains.

The smart city geo portals have ensured that every stake holder has information at his fingertip.

\subsection{RATING BY MINISTRY OF HOME \& URBAN AFFAIRS - GOVERNMENT OF INDIA}

As a GIS technology provider and a service provider for accurate Spatial Data creation Scanpoint Geomatics Limited has proved its merit. The ' 100 Smart Cities' mission initiated by the NITI AAYOG is continuously monitored and the progress is evaluated by the Government. The cities handled by SGL and the evaluated score are shown in Table_1 here. The case of Lucknow is reflected poorly due to severe lockdown conditions and the process of taking over the data is yet to be completed.

\begin{tabular}{|c|c|c|c|c|}
\hline $\begin{array}{l}\text { Sr. } \\
\text { No }\end{array}$ & Smart City & $\begin{array}{c}\text { Spatial } \\
\text { Readin } \\
\text { ess } \\
\text { Score }\end{array}$ & $\begin{array}{l}\text { Certificate } \\
\text { Level }\end{array}$ & URL \\
\hline 1. & Pune & $20 / 20$ & Connected & $\begin{array}{l}\text { 1.DMAF } \\
\frac{\text { (mohua.gov.in }}{2} \\
\text { 2.PowerPoint } \\
\frac{\text { Presentation }}{\text { (mohua.gov.in }} \\
\frac{2}{2}\end{array}$ \\
\hline 2. & Surat & $20 / 20$ & Connected & $\begin{array}{l}\text { 1.DMAF } \\
\frac{\text { (mohua.gov.in }}{2} \\
\text { 2.PowerPoint } \\
\underline{\text { Presentation }} \\
\frac{\text { (mohua.gov.in }}{2} \\
\end{array}$ \\
\hline 3. & Agra & $20 / 20$ & Explorer & $\begin{array}{l}\text { 1.DMAF } \\
\frac{\text { (mohua.gov.in }}{2} \\
\text { 2.PowerPoint } \\
\frac{\text { Presentation }}{\text { (mohua.gov.in }} \\
\text { ) }\end{array}$ \\
\hline 4. & Ranchi & $20 / 20$ & Explorer & $\begin{array}{l}\text { 1.DMAF } \\
\frac{\text { (mohua.gov.in }}{2} \\
\text { 2.PowerPoint } \\
\frac{\text { Presentation }}{\text { (mohua.gov.in }} \\
\text { L }\end{array}$ \\
\hline 5. & Dehradun & $20 / 20$ & Initiator & $\begin{array}{l}\text { 1.DMAF } \\
\frac{\text { (mohua.gov.in }}{2} \\
\text { 2.PowerPoint } \\
\frac{\text { Presentation }}{\text { (mohua.gov.in }} \\
\text { L }\end{array}$ \\
\hline
\end{tabular}

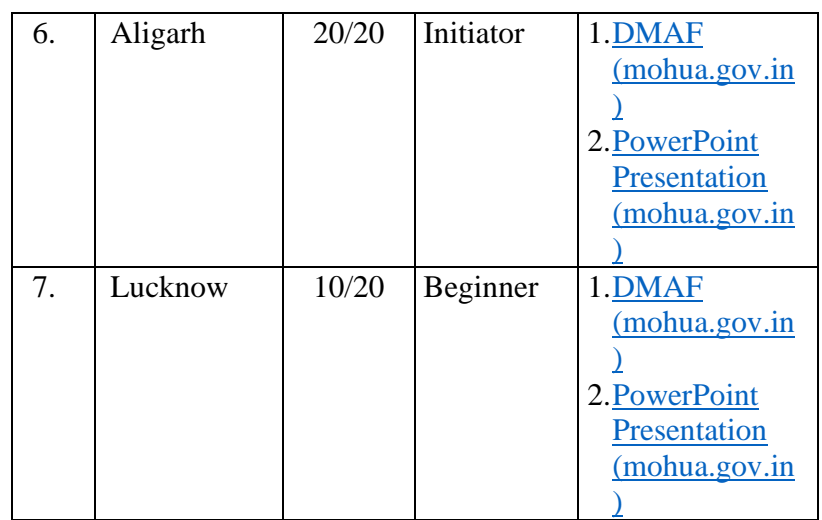

Table_1: Smart City Evaluation Score by Government

\subsection{THE WAY AHEAD:}

The primary requirement of establishing the geo-spatial identity of the various city components has been achieved through the creation of the spatial database. Individual departmental requirements of setting up IoT or SCADA based systems and integrating the same in the regular operations and maintenance is under progress. The pandemic and the Covid-19 related lockdowns have slowed down the execution and roll out of the smart city projects.

GIS is deployed at every stage of planning and development of a Smart City. The underlying framework is served by ICT (Information and Communications Technologies), while the focus is on the 'spatial' component i.e. the GIS. The common platform (IGiS Enterprise Suite) operates through all stages of the life cycle - from modelling, planning, building to managing across the full spectrum of functionalities.

The next step is to apply Artificial Intelligence techniques in several sectors. Establishing monitoring systems by equipping parks and other public facilities with automated lighting, and real time surveillance cameras leading to citizen safety. Integration of AI technologies for smart homes with water saving taps, automated switching off of lights and fans. AI technology can help predict crowd behaviour and the possibility of any disasters and help with response management in an uncertain event. The Smart command Centres in future will be equipped with sophisticated surveillance system which can track citizen movement, the potential crime incidents and general security of the citizens.

\section{REFERENCES:}

7.1 https://indiaai.gov.in/missions/smart-cities-mission

$7.2 \mathrm{http} / / /$ amrut.gov.in/content/innerpage/guidelines.php

7.3 https://www.sgligis.com/products/

7.4 https://gis.suratmunicipal,org

7.5 https://gis.pmc.gov.in

7.6 http://agrasmartcity.in (click on City GIS)

7.7 https://gis.rsccl.in/ 